\title{
Microbiological profile of bronchoalveolar lavage fluid in patients with chronic respiratory diseases: a tertiary care hospital study
}

\author{
Vivek KU ${ }^{1}$, Nutan Kumar DM ${ }^{2}$ \\ ${ }^{1}$ Ex Senior Resident, Department of Pulmonary Medicine, ${ }^{2}$ Junior Resident, Department of Medicine, Both are \\ affiliated with Kempegowda Institute of Medical Sciences (KIMS), Bangalore.
}

Address for correspondence: Dr. Vivek KU, Email: vivek.kotyal@gmail.com

\begin{abstract}
Objective: Chronic respiratory diseases account for 4 million deaths annually. Infections are most frequent cause of exacerbations. Bronchoalveolar lavage has improved sensitivity and specificity of diagnostic techniques in diagnosis of pulmonary infections. Hospital antibiograms are an important component of detecting and monitoring trends in antimicrobial resistance. Materials and Methods: Retrospectively BAL fluid reports of patients with chronic respiratory diseases undergoing bronchoscopy in KIMS Hospital were collected under aseptic precautions. Antibiotic and antifungal susceptibility testing was done for bacterial isolates and fungal isolates. Results: Among 100 BAL sample cultured for bacterial etiology, 38 samples showed growth, 56 samples showed no growth. Monomicrobial growth of the BAL culture was seen in 34 cases $(89 \%)$ and polymicrobial growth was seen in $4(11 \%)$. In the antimicrobial susceptibility testing, $100 \%$ sensitivity was noted to linezolid, levofloxacin, tetracycline, vancomycin, netilmycin and tobramycin. Pipercillintazobactum and imipenem show sensitivity of $96.2 \%$. Antibiotics showing high resistance pattern were ampicillin (73\%) and amoxicillin-clavulanic acid (52.3\%). On fungal culture, 27 cases showed growth, of which candida albicans was the most common isolate $(37 \%)$. Aspergillus accounted for 4 isolates (14.8\%), aspergillus niger being predominant. All isolates of candida were $100 \%$ susceptible to fluconazole, itraconazole and voriconazole except candida albicans, $10 \%$ showed resistance to voriconazole. All isolates of aspergilluis were $100 \%$ susceptible to voriconazole and $100 \%$ resistance to fluconazole. Conclusion: Bronchoalveolar lavage has improved sensitivity and specificity in diagnosis of pulmonary infections. An updated local antibiogram for each hospital based on local bacteriological patterns and susceptibilities is essential to guide initial empiric therapy.
\end{abstract}

Keywords: Bronchoalveolar lavage, Bacterial isolate, Fungal isolate, Antibiotic sensitivity, Candida, Klebsiella, aspergillus.

\section{Introduction}

Chronic respiratory diseases are a group of chronic disease affecting the airways and other structures of lungs. Common chronic respiratory diseases are asthma, bronchiectasis, chronic obstructive lung diseases, including chronic obstructive pulmonary disease, emphysema and bronchitis, chronic pleural disease, pneumoconiosis, pulmonary eosinophilia, pulmonary heart diseases and disease of pulmonary embolism, pulmonary hypertension,corpulmonale, sarcoidosis, sleep apnoea syndrome [1]. Other diseases like cystic fibrosis, pulmonary fibrosis and occupational lung diseases are included [2]. They present with symptoms of cough ,pain in throat or chest, abnormalities of

Manuscript received: $11^{\text {th }} \mathrm{Feb} 2016$

Reviewed: $20^{\text {th }}$ Feb 2016

Author Corrected: $28^{\text {th }}$ Feb 2016

Accepted for Publication: 01 ${ }^{\text {st }}$ March 2016 breathing, hemorrhages of respiratory passages, signs involving respiratory and circulatory system(asphyxia ,pleurisy, cardio respiratory arrest, abnormal sputum) [1]. Most common causes of infections in these patients are viruses and bacteria (75-80\%). Most frequent bacteria involved in exacerbations include Haemophilus influenzae, Streptococcus pneumoniae, Moraxella catarrhalis [3]. Chronic respiratory diseases account for 4 million deaths annually contributing to $5 \%$ of global deaths [1]. Measured in Disability Adjusted Life Years (DALY), in 2005 the burden of chronic respiratory diseases was projected to account for $4 \%$ of the global burden and $8.3 \%$ of the burden of chronic diseases [1]. In India, chronic respiratory disease accounted $7 \%$ deaths and 3\% DALYs lost [3]. The course of these 
diseases is punctuated by exacerbations. Exacerbations are associated with greater and irreversible decline in lung function, significant mortality and morbidity. Infections are most frequent cause of exacerbations [4]. Early diagnosis and proper choice of antimicrobials is crucial for management of these patients. Sputum culture yields diagnosis in fewer than $50 \%$ of patients with pneumonia [5]. The advent of bronchoscopy and quantitative invasive techniques like Bronchoalveolar lavage has improved sensitivity and specificity of diagnostic techniques in diagnosis of pulmonary infections [6].

\section{Aims and objectives}

- To detect pathogenic organism by microscopy of BAL fluid.

- Isolate and identify aerobic bacteria and fungi from BAL fluid specimen.

- To determine antimicrobial susceptibility pattern of the isolates.

\section{Material and methods}

This was a retrospective collection of data from January 2014 to July 2015 of BAL fluid specimens of patients with chronic respiratory diseases undergoing bronchoscopy in KIMS Hospital, Bangalore. BAL fluid specimens were collected under aseptic precautions and transported to the laboratory immediately for further processing. The sample was inoculated on Blood agar, chocolate agar and Macconkey agar using a sterile $4 \mathrm{~mm}$ nichrome loop $(0.01 \mathrm{ml})$, and incubated at $37 \mathrm{C}$ for 72 hours for quantitative bacterial culture using standard laboratory techniques. Sample was also inoculated in brain heart infusion broth. For growth positive plates, the colony forming units was calculated [7]. Direct microscopy with wet mount preparation (10\% potassium hydroxide) was done on part of the sample to rule out fungal filaments, and remaining part of the sample was centrifuged at 3000rpm for 15-20 minutes [8]. Supernatant was resuspended in phosphate buffer saline or $1-5 \mathrm{ml}$ of the sample itself subjected to Gram's stain for Bacteria or fungus, acid fast staining techniques like Ziehl-Neelsen stain to rule out Mycobacteria, Kinyoun's technique for Nocardia [9], May-Grunwald- Giemsa stain to rule out cysts of parasites like Pneumocystis [10] and fungus [11]. A part of centrifuged sample was also inoculated on sabouraud's dextrose agar for fungal culture and incubated for 4 weeks at 370C. Antibiotic susceptibility testing was done for bacterial isolates by Kirby-Bauer's disc diffusion method. Using commercially available MIC test strips (HiMedia Laboratories) antifungal susceptibility testing was done for yeast like fungal isolates by E-test for fluconazole.

\section{Inclusion criteria}

1. Adult patients with chronic respiratory diseases undergoing bronchoalveolar lavage.

\section{Exclusion criteria}

1. Patients with unstable cardiac conditions (recent myocardial infarction, cardiac arrhythmias etc.

2. Pregnant women.

3. Patients who did not give consent for the procedure

Statistical Analysis: Data collected will be analyzed using descriptive statistical methods by computing percentage, mean and standard deviation. Wherever necessary the results were depicted in the form of percentages.

\section{Results}

This study was conducted in the department of pulmonary medicine, Kempegowda Institute of Medical Sciences, Bangalore from January 2014 to July 2015. 100 BAL samples of patients with chronic respiratory diseases were studied to detect the presence of bacterial and fungal infections of lung. Age of the patients varied from 18-85 years. Out of 100 cases majority of cases $28(28 \%)$ were in the age group of $>60$ years, followed by $22 \%$ in $51-60$ years, $21 \%$ in $41-50$ years and $3 \%$ in the age group of 18-20 years. 61 cases were male and 39 cases were female.

Most of the cases in our study include patients with tuberculosis (16\%), COPD (15\%), asthma(15\%), bronchiectasis (7\%). Occupational lung diseases and chronic lung abscess accounted for only $2 \%$ of the cases respectively as shown in table1. In the study, cough with sputum production was the most common symptom present in $94 \%$ cases. Fever was the second most common symptom (60\%), followed by dyspnea in 59\%. 7 patients presented with hemoptysis who were diagnosed with bronchogenic carcinoma. Out of 100 cases $78 \%$ of the cases had radiological signs suggestive of lung infections. Among 100 BAL sample cultured for bacterial etiology, only 38 samples showed growth >10,000 CFU/ml, 56 
Table 1: Respiratory disease profile

\begin{tabular}{|l|l|l|}
\hline Disease & Cases & Percentage (\%) \\
\hline Chronic obstructive respiratory disease & 15 & 15 \\
\hline Asthma & 12 & 12 \\
\hline Interstitial lung disease & 13 & 13 \\
\hline Tuberculosis & 16 & 16 \\
\hline Malignancy & 10 & 10 \\
\hline Non resolving pneumonia & 7 & 7 \\
\hline Pleural diseases & 7 & 7 \\
\hline Sarcoidosis & 4 & 4 \\
\hline Chronic lung abscess & 2 & 2 \\
\hline Occupational lung disease & 2 & 2 \\
\hline Bronchiectasis & 7 & 7 \\
\hline Corpulmonale & 7 & 7 \\
\hline Total & $\mathbf{1 0 0}$ & $\mathbf{1 0 0}$ \\
\hline
\end{tabular}

Samples showed no growth. Monomicrobial growth of the BAL culture was seen in 34/38 cases (89\%) and polymicrobial growth was seen in $4 / 38(11 \%)$.

Table 2: Profile of infections.

\begin{tabular}{|l|l|l|}
\hline Types of organisms & Number of cases $\mathbf{( \% )}$ & Number of isolates (\%) \\
\hline Monomicrobial & $34(89.4 \%)$ & $34(80.9 \%)$ \\
\hline Polymicrobial & $4(10.5 \%)$ & $8(19 \%)$ \\
\hline Total & $\mathbf{3 8}(\mathbf{1 0 0 \% )}$ & $\mathbf{4 2}(\mathbf{1 0 0 \% )}$ \\
\hline
\end{tabular}

Table 3: Organisms in monomicrobial distribution

\begin{tabular}{|l|l|l|}
\hline Type of organisms & Number of isolates & Percentage (\%) \\
\hline Monomicrobial & $\mathbf{3 4}$ & $\mathbf{8 0 . 9}$ \\
\hline Klebsiella pneumonia & 7 & 16.6 \\
\hline Acinetobacter baumanii & 6 & 14.2 \\
\hline Enterococcus faecalis & 5 & 11.9 \\
\hline Escherichia coli & 4 & 9 \\
\hline Streptococcus pneumonia & 4 & 9 \\
\hline Staphylococcus aureus & 3 & 7 \\
\hline Enterobacter aerogenes & 2 & 4.7 \\
\hline Pseudomonas aeuroginosa & 1 & 2.3 \\
\hline Klebsiella oxytoca & 1 & 2.3 \\
\hline Serratia marcescens & 1 & 2.3 \\
\hline
\end{tabular}

Table 4: Organisms in polymicrobial distribution

\begin{tabular}{|l|l|l|}
\hline Type of organisms & Number of isolates & Percentage (\%) \\
\hline Polymicrobial & $\mathbf{8}$ & $\mathbf{1 9}$ \\
\hline Klebsiella oxytoca+ Escherichia coli & 2 & 4.7 \\
\hline Klebsiella pneumonia+ Enterococcus faecalis & 2 & 4.7 \\
\hline Klebsiella oxytoca + Staphylococcus aureus & 2 & 4.7 \\
\hline Enterobacter aerogenes+ Staphylococcus aureus & 2 & 4.7 \\
\hline
\end{tabular}


In the antimicrobial susceptibility testing done for isolates, $100 \%$ sensitivity was noted to linezolid, levofloxacin, tetracycline, vancomycin, netilmycin and tobramycin. Pipercillin-tazobactum and imipenem show sensitivity of $96.2 \%$. Antibiotics showing high resistance pattern were ampicillin (73\%) and amoxicillin-clavulanic acid (52.3\%). Antibiotic resistance pattern shown in table 4 .

Table 5: Antibiotic resistant pattern seen in different aerobic organisms

\begin{tabular}{|c|c|c|c|c|c|c|c|c|c|}
\hline $\begin{array}{l}\text { Antibiotic } \\
\text { s }\end{array}$ & $\begin{array}{l}\text { Klebsiella } \\
\text { pneumoni } \\
\mathbf{a}(8)\end{array}$ & $\begin{array}{l}\text { Acineto } \\
\text { bater } \\
\text { bauman } \\
\text { ii(6) }\end{array}$ & $\begin{array}{l}\text { Enteroc } \\
\text { occus } \\
\text { fecalis }(6)\end{array}$ & $\begin{array}{l}\text { Staph } \\
\text { aureu } \\
s(5)\end{array}$ & $\begin{array}{l}\text { E.co } \\
\text { li(5) }\end{array}$ & $\begin{array}{l}\text { Streptoc } \\
\text { occus } \\
\text { pneumon } \\
\text { ia(4) }\end{array}$ & $\begin{array}{l}\text { Enteroba } \\
\text { cter } \\
\text { aerogenes } \\
\text { (3) }\end{array}$ & $\begin{array}{l}\text { Klebsiel } \\
\text { la } \\
\text { oxytoca } \\
\text { (3) }\end{array}$ & $\begin{array}{l}\text { Pseudo } \\
\text { monas } \\
\text { aerugin } \\
\text { osa(1) }\end{array}$ \\
\hline Amikacin & 0 & $1(16 \%)$ & 0 & 0 & $\begin{array}{l}1(20 \\
\%)\end{array}$ & - & $1(33.3 \%)$ & 0 & 0 \\
\hline $\begin{array}{l}\text { Amoxicilli } \\
\text { n/clavulani } \\
\text { c acid }\end{array}$ & $5(62.5 \%)$ & $3(50 \%)$ & $1(16.7 \%)$ & $\begin{array}{l}2(66.6 \\
\%)\end{array}$ & $\begin{array}{l}5(10 \\
0 \%)\end{array}$ & $1(25 \%)$ & $3(100 \%)$ & $\begin{array}{l}3(100 \% \\
)\end{array}$ & 0 \\
\hline $\begin{array}{l}\text { Clindamyc } \\
\text { in }\end{array}$ & - & - & $1(16.7 \%)$ & - & - & $1(25 \%)$ & - & - & - \\
\hline $\begin{array}{l}\text { Cefoperazo } \\
\text { ne }\end{array}$ & $2(25 \%)$ & $3(50 \%)$ & $1(16.7 \%)$ & 0 & $\begin{array}{l}3(60 \\
\%)\end{array}$ & $1(25 \%)$ & $1(33 \%)$ & $\begin{array}{l}2(66.6 \% \\
)\end{array}$ & - \\
\hline Cefepime & & & $1(16.7 \%)$ & 0 & $\begin{array}{l}3(60 \\
\%)\end{array}$ & $1(25 \%)$ & $1(33 \%)$ & $\begin{array}{l}2(66.6 \% \\
)\end{array}$ & 0 \\
\hline Imipenem & 0 & $1(16 \%)$ & - & 0 & 0 & - & 0 & 0 & 0 \\
\hline Linezolid & - & - & 0 & - & - & 0 & - & - & - \\
\hline $\begin{array}{l}\text { Vancomyci } \\
\text { n }\end{array}$ & - & - & 0 & - & - & 0 & - & - & - \\
\hline $\begin{array}{l}\text { Piperacillin } \\
\text { /Tazobacta } \\
\mathrm{m}\end{array}$ & 0 & $1(16 \%)$ & - & 0 & 0 & - & 0 & 0 & 0 \\
\hline
\end{tabular}

Out of 100 cases studied, 9 cases were positive for acid fast bacilli with ziehl-neelson stain, 23 cases were positive for fungal elements with wet mount examination. None of them were positive for nocardia screened by modified kinyoun's stain with $1 \%$ sulphuric acid. On gram staining for fungus, 26 cases showed the presence of gram positive budding yeast like cells and hyphae structures. 77 cases showed no evidence of fungus on gram stain. On May-Grunwald -Geimsa staining, 14 cases showed budding yeast like cells and hyphal structures. On fungal culture, 27 cases showed growth on Sabouraud's dextrose agar and BACTEC mycosis IC/F bottles. Out of 27 species of fungus isolated, candida albicans was the most common isolate (37\%). Aspergillus accounted for 4 isolates (14.8\%), aspergillus niger being predominant.only one isolate of candoda dublinensis was seen as shown in table 4

Table 6: Organisms isolated in fungal culture.

\begin{tabular}{|l|l|}
\hline Organisms & Number \\
\hline Candida albicans & 10 \\
\hline Candida parapsilosis & 4 \\
\hline Candida glabrata & 4 \\
\hline Candida tropicalis & 4 \\
\hline Candida dublinensis & 1 \\
\hline Aspergillus niger & 2 \\
\hline Aspergillus flavus & 1 \\
\hline Aspergillus fumigates & 1 \\
\hline Total & $\mathbf{2 7}$ \\
\hline
\end{tabular}


All isolates of candida were $100 \%$ susceptible to fluconazole, itraconazole and voriconazole except candida albicans, $10 \%$ showed resistance to voriconazole. Amphotericin B resistance was seen in candida albicans (10\%), candida tropicalis $(75 \%)$, candida glabrata and candida parapsilosis. $25 \%$ of candida tropicalis were resistance to ketoconazole. All isolates of aspergilluis were $100 \%$ susceptible to voriconazole and $100 \%$ resistance to fluconazole. Asspergillus niger and aspergillus fumigates showed $100 \%$ susceptibility to itraconazole, whereas aspergillus flavus was resistant. Aspergillus fumigatus was resistance to amphotericin B and ketoconazole.

\section{Discussions}

Chronic respiratory diseases represent a public health challenge in both industrialized and developing countries because of their frequency and economic impact. It is major cause of mortality and morbidity across the globe. This study was conducted to evaluate the bacterial and fungal agents causing infections in patients with chronic respiratory disease and with perspective of evaluating their sensitivity to different antibiotics. In this study, most of the chronic respiratory diseases belong to age group of more than 45 years which correlated with the study conducted by Mullerova et al [12] (45\%) and Merino- Sanchez et al (60\%). [13] Age above 65 years is the risk factor for developing pneumonia. Use of inhalational steroids lowers the oral defence and pay route for microbial colonization.

Bronchoalveolar lavage provides a very usefull tool for diagnosing lower respiratory tract infections. The present study yielded positive bacterial BAL cultures in $38 \%$ of the cases of suspected lung infections. This is in contrast to other studies like Velez et al [14] and Kottmann et al [15], where the positive yield was 51.6\% and 55.8\% respectively. The lower positivity rate in the present study might be because the study was done in general population, whereas other studies quoted above were done in immunocompromised patients. In the present study, aerobic gram negative and gram positive bacteria constituted $65.7 \%$ and $34.3 \%$ of the isolates respectively, which correlates with the study conducted by Groenewegen and Wouters in patients with COPD with suspected pneumonia, where aerobic gram negative and gram positive bacteria constituted $71 \%$ and $27 \%$ of the isolates respectively [16]. Klebsiella (26\%) was the most common pathogen isolated from our study which correlates with studies conducted by Lin SH et al [17] (19.6\%) and Singh AK et al.[18] Klebsiella is a part of normal flora of the mouth and most widely associated with pneumonia in a hospitalised patients and elderly. Hence, its predominance may be related to the predominate elderly population in our study. Comparision among different studies shown in table 5.

Table 7: Comparision of bacterial flora isolated from various studies on chronic respiratory disease.

\begin{tabular}{|c|c|c|c|c|c|c|}
\hline \multirow[t]{2}{*}{ Study } & \multirow{2}{*}{$\begin{array}{l}\text { Total } \\
\text { isolates }\end{array}$} & \multicolumn{2}{|c|}{ Percentage of isolates } & \multirow[b]{2}{*}{ S. aureus } & \multirow[b]{2}{*}{ S. pneumoniae } & \multirow[b]{2}{*}{$\begin{array}{l}\text { Pseudomonas } \\
\text { aeroginosa }\end{array}$} \\
\hline & & klebsiella & Acinetobacter & & & \\
\hline $\begin{array}{l}\text { Torres et al } \\
\text { [19] }\end{array}$ & 73 & - & - & - & $43 \%$ & - \\
\hline $\begin{array}{l}\text { Lin SH et } \\
\text { al [17] }\end{array}$ & 328 & $19.6 \%$ & $6.9 \%$ & $6.1 \%$ & $2.4 \%$ & $16.8 \%$ \\
\hline $\begin{array}{l}\text { Bari et al } \\
{[20]}\end{array}$ & 60 & $13.3 \%$ & $6 \%$ & - & $3 \%$ & $25 \%$ \\
\hline Our study & 42 & $26 \%$ & $14.2 \%$ & $11.9 \%$ & $9.5 \%$ & $2 \%$ \\
\hline
\end{tabular}

Enterococcal infections are common in those with underlying diseases such as after major surgery, immunosuppression, organ transplant patients and cardio-pulmonary disease. The present study showed $14.2 \%$ isolates of enterococcus faecalis, which is in agreement with study conducted by Bonten et al [21] (13.3\%) and Hohenadel et al [22] (9.9\%) on pneumonia patients. The present study showed maximum resistance of organisms to antibiotics like ampicillin (73\%), amoxyclav (52\%), cefuroxime (44\%), cefaperazone (31.7\%) and cotrimaxozole (39\%). In the present study, $9 \%$ of the patients were diagnosed with mycobacterium tuberculosis. This is correlated to study conducted in immunocompromised patients with pneumonia, where $6.6 \%$ of the cases were due to tuberculosis. The increased incidence of fungal lung infection is due to increase in population of immunocompromised and susceptible patients like those on steroids, chronic diseases like COPD, cirrhosis of liver etc. The increase use of antibiotic and antifungal prophylaxis has also lead to colonization of fungi in the respiratory tract. All these factors contribute to the recent explosion in number of cases of 
fungal infection. The prevalence of fungal infection in the present study was $27 \%$, which was similar to study conducted by Hohenadel et al where fungal etiology accounted for 35\% [22]. Among the isolates, 23 were of candida species and 5 were of aspergillus species. These findings are in concordance with a study conducted in patients with malignancy with suspected lung infections, where 23 isolates of candida species and 7 isolates of aspergillus species were demonstrated. Another study conducted in patients with chronic respiratory diseases in Himalayan region had 14 isolates of candida and 13 isolates of aspergillus [23]. Candida albicans (37\%) was the most frequent isolate in the present study among candida species. This is in agreement with the study conducted by Phukan AC et al which showed 76\% isolation of candida albicans [24]. Similar to other studies aspergillus fumigatus was the most common isolate among aspergillus species.[25], [26] The isolation of aspergillus in a healthy person would be contaminant, but population included in the present study already had decreased immunity as they had chronic lung disease and most of them were on steroid treatment for their exacerbations. Hence these cases need early initiation of antifungal treatment.

Available studies on fluconazole susceptibility of candida albicans isolates from India have showed either no resistance or a very low percentage of resistance. The present study showed $100 \%$ susceptibility to fluconazole. The present study has recorded high resistance to amphotericin B (75\%), which correlated with the study conducted by Changdeo S Aher which showed high resistance to amphotericin B in C. tropicalis and C. glabrata [27]. Emergence of azole resistance in aspergillus is demonstrated in various studies. Voriconazole is preferred therapy for invasive aspergillosis, high susceptibility to voriconazole in our study is a positive factor for the patients which correlated with studies conducted by Snelders et al and Denning DW et al [28], [29] There is emergence of multidrug resistant strains of fungus at an alarming rate. Hence it is necessary to determine the antifungal susceptibility to decrease the morbidity and mortality and also prevent the emergence of drug resistance to higher drugs. The limitation of the study were small sample size limits the generalization, Outcome of all the patients studied could not be monitored. Anaerobic organisms and all antibiotic groups could not be studied because of technical limitations.

\section{Conclusion}

Delays in initiation of antibiotic treatment may lead to poor outcomes. There is a risk of emergence of MDR pathogens with inadequate, inappropriate antibiotic treatment. To initiate an empiric antimicrobial therapy we should have the knowledge of microbial flora of the locality and their sensitivity and resistance patterns, such information needs to be analysed periodically and institution based antibiotic policies formed from time to time and made available to all consultants treating infectious diseases. Hospital antibiograms are an important component of detecting and monitoring trends in antimicrobial resistance. It would be ideal, through multicenter studies, to generate nationwide or more appropriately region-specific antibiograms,

\section{Funding: Nil}

Conflict of interest: None.

Permission of IRB: Yes

\section{References}

1. WHO. Global surveillance, prevention and control of CHRONIC RESPIRATORY DISEASES.A comprehensive approach;2007:514.

2. Australian Institute of Health and Welfare. chronic respiratory conditions including asthma and COPD

[internet].http:/www.aihw.gov.au/chronicrespirator conditions/.last accessed on Nov 2013.

3. Koul PA.Chronic obstructive pulmonary disease: Indian guidelines and the road ahead. Lung India. 2013 Jul;30(3):175-7. doi: 10.4103/0970-2113.116233.

4. Meduri GU, Beals DH, Maijub AG, Baselski V. Protected bronchoalveolar lavage. A new bronchoscopic technique to retrieve uncontaminated distal airway secretions. Am Rev Respir Dis. 1991 Apr;143(4 Pt 1):855-64.

5. Meduri GU, Beals DH, Maijub AG, Baselski V. Protected bronchoalveolar lavage. A new bronchoscopic technique to retrieve uncontaminated distal airway secretions. Am Rev Respir Dis. 1991 Apr;143(4 Pt 1):855-64.

6. Joao Carlos Pereira Gomes, Wilson L Pedreira Jr, Evangelina M P, Araujo A, Francisco G Soriano, Elnara M Negri et al.Impact of BAL in the Management of Pneumonia With Treatment failure-Positivity of BAL Culture Under Antibiotic Therapy. CHEST 2000;118:1739-46. 
7. Mary K. York,Peter Gilligan, and Deirdre L Church .Processing and Interpretation of Lower respiratory tract specimens.In:Lynne S Garcia,Henry D Isenberg(eds). Clinical Microbiology Procedure Handbook. $2^{\text {nd }}$ ed.ASM PRESS,Washington DC 2007;1:3.11.2.

8. Initial processing, inoculation and incubation of aerobic bacteriology specimens. In:Henry D Isenberg, editor. Clinical Microbiology Procedure Handbook. $1^{\text {st }}$ Ed.ASM PRESS, Washington DC.1992;1:1.4.12.

9. Kahn Frederick and Jones J Jefrey.Analysis of Bronchoalveolar lavage specimen from immunocompromised patients with protocol applicable in microbiology Laboratory.J of Clin Microbiology 1988 june;1150-1155.

10. Rasmussen TR, Korsgaard J, Møller JK, Sommer T, Kilian M. Quantitative culture of bronchoalveolar lavage fluid in community-acquired lower respiratory tract infections. Respir Med. 2001 Nov;95(11):885-90.

11. Knox KS, Meinke L. Role of bronchoalveolar lavage diagnostics in fungal infections. Clin Chest Med. 2009 Jun;30(2):355-65, viii. doi: 10.1016/j.ccm.2009.02.010.

12. Müllerová H, Shukla A, Hawkins A, Quint J. Risk factors for acute exacerbations of COPD in a primary care population: a retrospective observational cohort study. BMJ Open. 2014 Dec 18;4(12):e006171. doi: 10.1136/bmjopen-2014-006171.

13. Merino-Sánchez M, Alfageme-Michavila I, ReyesNúñez N, Lima-Alvarez J. [Prognosis in patients with pneumonia and chronic obstructive pulmonary disease]. Arch Bronconeumol. 2005 Nov;41(11):60711.

14. Vélez L1, Correa LT, Maya MA, Mejía P, Ortega J, Bedoya V, Ortega H. Diagnostic accuracy of bronchoalveolar lavage samples in immunosuppressed patients with suspected pneumonia: analysis of a protocol.. Respir Med. 2007 Oct;101(10):2160-7.

15. Kottmann RM, Kelly J, Lyda E, Gurell M, Stalica J, Ormsby W, Moon K, Trawick D, Sime PJ. Bronchoscopy with bronchoalveolar lavage: determinants of yield and impact on management in immunosuppressed patients. Thorax. 2011 Sep;66(9):823. doi: 10.1136/thx.2010.145540.

16. Kottmann RM, Kelly J, Lyda E, Gurell M, Stalica J, Ormsby W, Moon K, Trawick D, Sime PJ. Bronchoscopy with bronchoalveolar lavage: determinants of yield and impact on management in immunosuppressed patients. Thorax. 2011 Sep;66(9):823. doi: 10.1136/thx.2010.145540. Epub 2010 Sep 13.

17. Lin SH, Kuo PH, Hsueh PR, Yang PC, Kuo SH. Sputum bacteriology in hospitalized patients with acute obstructive pulmonary an emphasis on Klebsiella Pseudomonas aeruginosa. Respirology. 2007 Jan;12(1):81-7.

18. Singh AK, Sen MR, Anupurba S, Bhattacharya P. Antibiotic sensitivity pattern of the bacteria isolated from nosocomial infections in ICU. $\mathbf{J}$ Commun Dis. 2002 Dec;34(4):257-63.

19. Torres A, El-Ebiary M. Invasive diagnostic techniques for pneumonia: protected specimen brush, bronchoalveolar lavage, and lung biopsy methods. Infect Dis Clin North Am 1998;12: 701-22.

20. Bari MR, Hiron MM, Zaman SM, Rahman MM, Ganguly KC. Microbes responsible for acute exacerbation of COPD. Mymensingh Med J. 2010 Oct;19(4):576-85.

21. Bonten MJ, Weinstein RA. The role of colonization in the pathogenesis of nosocomial infections. Infect Control Hosp Epidemiol. 1996 Mar;17(3):193-200.

22. Hohenadel IA, Kiworr M, Genitsariotis R, Zeidler D, Lorenz J. Role of bronchoalveolar lavage in immunocompromised

patients with pneumonia treated with

a broadspectrum antibiotic and antifungal regimen.

Thorax. 2001 Feb;56(2):115-20.

23. Biswas D, Agarwal S, Sindhwani G, Rawat J. Fungal colonization in patients with chronic respiratory diseases from Himalayan region of India. Ann Clin Microbiol Antimicrob. 2010 Sep 20;9:28. doi: 10.1186/1476-0711-9-28. 
24. Phukan AC, Sarmabordoloi JN, Mahanta J. Bronchopulmonary candidiasis in a tertiary referral hospital of Assam, India. Indian J Med Sci. 2000 Nov;54(11):491-4.

25. Cruz C H R, Vieille O P, Fuentes H D, Ponce E E, Piontelli L E. Frequency of pulmonary mycoses determined by analyzing lung secretion samples. Rev Med Chil. 2012 May;140(5):595-601. doi: 10.4067/S0034-98872012000500006.

26. Tarrand JJ, Lichterfeld M, Warraich I, Luna M, Han XY, May GS, Kontoyiannis DP. Diagnosis of invasive septate mold infections.A correl ation of microbiological culture and histologic orcytol ogic examination. Am J Clin Pathol. 2003 Jun;119(6):854-8.
27. Changdeo, S.A. Species distribution, virulence factors and antifungal susceptibility profile of Candida isolated from Oropharyngeal lesions of HIV infected patients. Int J Curr Microbiol App Sci., 3(1): 453-460 (2014)

28. Snelders E, van der Lee HA, Kuijpers J, Rijs AJ, Varga J, Samson RA, Mellado E, Donders AR, Melchers WJ, Verweij PE. Emergence of azole resistance in Aspergillus fumigatus and spread of a single resistance mechanism. PLoS Med. 2008 Nov 11;5(11):e219. doi: 10.1371/journal.pmed.0050219.

29. Denning DW, Ribaud P, Milpied N, Caillot D, Herbrecht R, Thiel E, Haas A, Ruhnke M, Lode H. Efficacy and safety of voriconazole in the treatment of acute invasive aspergillosis. Clin Infect Dis. 2002 Mar 1;34(5):563-71. Epub 2002 Jan 22.

\section{How to cite this article?}

Vivek KU, Nutan Kumar DM Microbiological profile of bronchoalveolar lavage fluid in patients with chronic respiratory diseases: a tertiary care hospital study. Int J Med Res Rev 2016;4(3):330-337. doi: 10.17511/ijmrr.2016.i03.08. 